\title{
Suppurative cystadenoma of ovary with left ventricular thrombus: a case report
}

\author{
Ivana Petrović Juren*, Vlasta Soukup Podravec, Andreja Čleković-Kovačić, Mislav Klobučić, \\ Kristina Milevoj Križić \\ Bjelovar General Hospital, Bjelovar, Croatia
}

Left ventricular thrombus (LVT) is a frequent complication observed after myocardial infarction, in a patient with congestive heart failure (CHF) and dilated cardiomyopathy. LVT is usually associated with severe wall motion abnormality, severe hypokinesis, akinesis, dyskinesis or aneurysmal dilatation. LVT rarely forms with normal wall motion and systolic function of left ventricule, for example in patients with inflammatory bowel diseases or malignancy. The process of clot formation is explained by a hypercoagulable state due to increased concentrations of prothrombotic factors.

We report a case of a 57-year old woman, who was admitted to our hospital with a few months history of progressive anemia, abdominal pain, fever, weight loss and erythema nodosum. Her past medical history included hypothyroidism, chronic obstructive pulmonary disease and nicotinism.

Radiological examination revealed tumefaction in the area of terminal ileum. Immunological and tumor markers were normal. Echocardiography showed normal left ventricular size and systolic function. There was an abnormal mass, size $15 \times 8 \mathrm{~mm}$, attached to the apical third of interventricular septum which was protruding into the cavity of left ventricule (differential diagnosis - thrombus versus tumor). Since the patient had very high serum levels of inflammatory factors, prophylactic dose of low molecular heparin was added to the therapy. Due to the clinical presentation associated with ileus and suspected intra-abdominal abscess, and need for emergent surgical evaluation, the patient was transferred to Cancer Clinic. The patient underwent surgical resection of the terminal ileum and ovariectomy. Pathohistology showed suppurative cystaednoma of ovary. Warfarin therapy continued. Follow up echocardiography showed complete resolution of previously existed cardiac mass in the left ventricule. A complete patient's recovery was noted.

It was felt that the left ventricule thrombus was formed in the setting of an inflammatory, prothrombotic environment. After removal of causative inflammatory/prothrombotic elements along with added antiacoagulation therapy, full recovery was achieved.

KEYWORDS: ovarian cystadenoma, left ventricular thrombus, echocardiography.

\section{Received: $20^{\text {th }}$ Mar 2013}

*Address for correspondence: Opća bolnica Bjelovar, Mihanovićeva 8, HR-43000 Bjelovar, Croatia.

Phone: +385-43-279-190

Email: ivanapetro@yahoo.co.uk

\section{Literature}

1. Saleh T. Left ventricular thrombosis in ulcerative colitis. Case Rep Gastroenterol. 2010;21;4:220-3.

2. Chin WW, Van Tosn A, Hecht SR, Berger M. Left ventricular thrombosis with normal left ventricular function in ulcerative colitis. Am Heart J. 1988;116(2 Pt1):562-3.

3. DeGroat TS, Parameswaran R, Popper PM, Kotler MN. Left ventricular thrombosis in association with normal left ventricular motion in patients with malignancy. Am J Cardiol. 1985;56(12):827-8.

4. Ozkan B, Emel M. Ozdemir M, et al. M-mode, 2-D and Doppler echocardiographic study in 65 patients with Behçet's syndrome. Eur Heart J. 1992;13:638-41. 